\title{
Perceptions of Health-Related Information on Facebook: Cross-Sectional Study Among Vietnamese Youths
}

Melvyn WB Zhang ${ }^{1}$, MBBS, DCP, MRCPsych; Bach Xuan Tran ${ }^{2,3}$, PhD; Huong Thi $\mathrm{Le}^{2}, \mathrm{MD}$, PhD; Hinh Duc Nguyen ${ }^{4}, \mathrm{MD}$, PhD; Cuong Tat Nguyen ${ }^{5}, \mathrm{MPH}$; Tho Dinh Tran ${ }^{6}, \mathrm{MD}, \mathrm{PhD}$; Carl A Latkin ${ }^{3}$, PhD; Roger CM Ho MBBS, MRCPsych

\footnotetext{
${ }_{1}^{1}$ Biomedical Global Institute of Healthcare Research and Technology, National University of Singapore, Singapore, Singapore

${ }^{2}$ Institute for Preventive Medicine and Public Health, Hanoi Medical University, Hanoi, Vietnam

${ }^{3}$ Bloomberg School of Public Health, Johns Hopkins University, Baltimore, MD, United States

${ }^{4}$ Hanoi Medical University, Hanoi, Vietnam

${ }^{5}$ Institute for Global Health Innovations, Duy Tan University, Da Nang, Vietnam

${ }^{6}$ Vietnam-Germany Hospital, Hanoi, Vietnam

${ }^{7}$ Yong Loo Lin School of Medicine, National University of Singapore, Singapore, Singapore
}

\section{Corresponding Author:}

Cuong Tat Nguyen, MPH

Institute for Global Health Innovations

Duy Tan University

182 Nguyen Van Linh, Thanh Khe district

Da Nang,

Vietnam

Phone: 84982228662

Email: cuong.ighi@gmail.com

\section{Abstract}

Background: While health information websites may have previously been the core source of information about health-related conditions on the Internet, social networking sites are increasingly replacing those websites as a source of health-related information. The increasingly popularity of social networking sites among the general population has consequential impact on health policies as well as health-related interventions. To date, there remains a paucity of research conducted in developing countries like Vietnam looking at the influence of social networking sites.

Objective: Our goal is to establish the baseline use of Facebook among Vietnamese youths and establish their perception of the reliability and usefulness of health-related information that they previously encountered while using the social networking site.

Methods: An online cross-sectional study was conducted from August 2015 to October 2015. Respondent-driven sampling (RDS) technique was used in the recruitment of participants. Sociodemographic, health status, behaviors, Facebook use and belief of information on Facebook, and interpersonal influence of social network sites were collected via an online structured questionnaire.

Results: Among 1080 participants, 72.87\% (787/1080) reported being interested in health information on Facebook, and 50.74\% (548/1080) and $17.50 \%$ (189/1080) perceived the information to be reliable and useful, respectively. A total of 10.93\% (118/1080) of the participants also reported that they would follow the health advice they obtained from Facebook. Of significance, $7.13 \%$ (77/1080) of the participants also reported peer influences on their behavior. Factors that mediate Vietnamese perceptions of the information online include gender, level of perceived stress, age, educational level, and interpersonal influences from Facebook.

Conclusions: Our study is perhaps one of the first conducted in Vietnam that looks at the relationship between health information on Facebook and factors that might influence young Vietnamese perceptions of the information and the consequential use of that information.

(Interact J Med Res 2017;6(2):e16) doi: 10.2196/ijmr.8072 


\section{KEYWORDS}

health information; social media; Facebook; beliefs

\section{Introduction}

Over the past decade, there have been rapid advances in Internet as well as mobile technologies. Such rapid advances in technology have revolutionized health care. Aside from the introduction and implementation of electronic medical records in the health care setting, the availability of the Internet has allowed individuals to seek out information about various medical disorders more readily [1]. It is pertinent to note that the influence of such technological advances is not limited to developed countries. Developing countries such as Vietnam are also becoming increasingly more connected to the Internet [2]. Prior studies conducted have reported that the penetration rate of the Internet in Vietnam has increased approximately threefold since 2005 [2].

More recent research has reported that youths in Vietnam tend to use the Internet, especially using their mobile devices, and those who are younger are also more likely to use social networking sites as well as messaging apps [3].

While technology has transformed how health care professionals function in their day to day activities, it has also affected the general public. There are myriad studies highlighting how technology has empowered individuals and transformed the way they seek out health-related information on the Internet. While health information websites may have previously been the core source of information about health-related conditions on the Internet, social networking sites are increasingly replacing those websites as a source of health-related information. Prior studies have reported there has been a paradigm shift in terms of information-seeking from the health information websites to social media of late [4]. A recent study has looked into how young adults sought information about diabetes and mental health online [5]. Based on the semistructured interviews conducted, it was noted that while young adults do use search engines to look for health-related information, they are increasingly using social media to seek health-related information as well [5]. The increasing popularity of social networking sites among the general population has consequential impact on health policies as well as health-related interventions. Huesch et al [6] have examined how social networking sites such as Facebook could potentially be used for public health interventions. Other research has highlighted the potential utility of social networking sites in reaching out to individuals in the general population who have experienced auditory hallucinations [7]. The research also reported how social networking sites such as Facebook could potentially be used as a form of support and a therapeutic tool for participants who are distressed by their hallucinations [7]. Aside from the use of Facebook for hallucinations, other researchers have proposed that Facebook could also be used to help reduce the incidence of problem drinking among university students through modification of social norms about drinking [8]. Facebook has also been used previously in the analysis of beliefs about common disorders such as attention-deficit hyperactivity disorder [9]. Clearly, there is a huge amount of potential for social networking sites to not only disseminate health-related information but also potentially be used as an intervention.

Granted, prior studies have documented the utility of Facebook as an intervention as well as a resource for health-related information. More recently, a study was conducted to determine the factors associated with how college students seek out health-related information using social networking sites [10]. Another study reported that various sociodemographic variables as well as the sources of the information are influential in participant receptiveness and preferences. Other research has demonstrated how Facebook could help augment tobacco prevention strategies taught in the classroom setting [11]. Notably, that study reported that a good proportion of students posted antitobacco messages on their social media account days after being exposed to tobacco prevention strategies in a classroom setting. Clearly, it is evident that Facebook is being used and perceived as a good tool to communicate health-related information [11].

In a developing country like Vietnam, with the rapid proliferation and increasing affordability of the Internet, it is thus pertinent for us to understand how youths perceive the health-related information on social networking sites. An understanding of this is pertinent prior to the conceptualization and implementation of interventions to deal with public health problems, modeling against research that has been done in the west. To our knowledge, there have not been any prior studies looking into how youths seek out health-related information on social networking sites in Vietnam. Here, thus far, the most common methodology of disseminating health-related information is via school-based campaigns [12].

The aim of this study is to establish the baseline use of Facebook among Vietnamese youths and establish their perception of the reliability and usefulness of health-related information that they previously encountered while using the social networking site. This study also seeks to determine how Vietnamese youths use the information they have obtained from online social networking sites. In addition, this study seeks to determine if there are other variables that might affect youth perceptions and receptiveness, such as their baseline health status. Understanding this information will help guide future public health interventions that use social networking sites as an interventional tool.

\section{Methods}

\section{Study Setting and Population}

In order to achieve the study's objectives, an online cross-sectional study was conducted from August 2015 to October 2015 in Vietnam. The inclusion criteria for participation in the study include the following: aged 15 to 25 years, currently residing in Vietnam, and having access to an email or social network site account. There are no specific exclusion criteria for this study. 


\section{Respondent-Driven Sampling and Sample Size}

For this cross-sectional study, the investigators made use of the respondent-driven sampling (RDS) technique in the recruitment of the participants. The sampling technique is as described elsewhere [13-15]. First, several core participants were recruited from high schools (Hung Yen high school and Phan Boi Chau high school) and universities (Hanoi Medical University and Vietnam National University) in Vietnam. The core participants were carefully selected to reflect the diversity of the Vietnamese population, taking into consideration age, gender, and level of education. Participants in the core groups were required to give their informed consent for the study and were told they would be required to make use of their email or social network site accounts to recruit other students to participate in the study. All participants in the core group were required to complete the Web-based study questionnaire prior to recruiting other participants. The invited participants were provided with the Web link of the survey form for them to complete the same questionnaire. There was no predefined end date of recruitment. The network was allowed to expand until it was deemed to be not able to expand any further. The survey was then deemed complete.

All the participants in the core group as well as the participants whom they invited were included in the final sample. Duplicate participants were identified through email, and amounted to a total of 7 cases, while 3 cases did not meet the inclusion criteria. Participants who did not complete at least $60 \%$ of the questions in the survey questionnaire were also excluded from the analysis. The resultant cumulative total sample size amounted to 1080 participants.

\section{Web Survey Design}

The cross-sectional survey was implemented and deployed using Google Forms. All the data acquired from the Web-based study was stored on Google's Health Insurance Portability and Accountability Act-compliant server. Prior to the commencement of the survey, all participants were provided with information about the study's purposes and methodology as well as information about the principal and coinvestigators. The questionnaire survey comprised 40 questions, and participants were required to answer 23 questions. The Web survey was piloted among a group of 20 youths of different ages and genders prior to the actual implementation. The participants in the pilot group assisted in the assessment of the usability and reliability of the Web-based survey across a variety of devices and operating system platforms. For the questionnaire, a logic check was implemented in order to ensure that the answers provided corresponded to the theme of the questions.

The Web-based survey included the following questionnaires:

- Baseline demographics questionnaire: Baseline demographic information such as age, gender, educational level, occupational status, marital status, ethnicity, and religion beliefs were acquired from the participants.

- Health-related quality of life (HRQOL): HRQOL was measured by using the EuroQol 5 dimension 5 level (EQ-5D-5L) instrument. The HRQOL questionnaire included 5 domains: mobility, self-care, usual activities, pain/discomfort, and anxiety/depression, with 5 levels of response: no problems, slight problems, moderate problems, severe problems, and extreme problems, giving 3125 health states with respective single indexes. To compute those indexes, the interim scoring for the EQ-5D-5L from the cross-walk value set of Thailand was used due to the unavailability of the Vietnamese population's reference [16]. Additionally, the EQ-VAS (visual analog scale) assessed the self-rated health of respondents on a $20-\mathrm{cm}$ vertical scale with the endpoint range from 0 to 100 points, labeled "the best health you can imagine" and "the worst health you can imagine." The validated Vietnamese version of the EQ-5D-5L has been used elsewhere [13,14,17-22].

- Stress measurement: The short-form Perceived Stress Scale (PSS) was used to measure the stress of participants in the last 30 days. This instrument included 4 items with a 5-point scale: never (0), almost never (1), sometimes (2), fairly often (3), very often (4). Two items were negatively coded ("In the last month, how often have you felt that you were unable to control the important things in your life?" and "In the last month, how often have you felt difficulties were piling up so high that you could not overcome them?") and 2 items are positively coded ("In the last month, how often have you felt confident about your ability to handle your personal problems?" and "How often have you felt that things were going your way?"). In scoring the stress measure, positive items are reverse scored, and then all items are summed (scores ranging from 0 to 16 for the 4-item scale). Higher scores indicate greater stress [23].

- Risk behaviors: Questions were asked as to whether participants have had other risk behaviors such as smoking tobacco products or use of alcohol. To quantify the severity of the alcohol use disorder, we used the Alcohol Use Disorders Identification Test-Consumption (AUDIT-C) instrument, which is a short version of the Alcohol Use Disorders Identification Test. This tool consisted of 3 questions with scoring from 0 to 12 , with a higher score indicative of a higher risk of alcohol dependence. If male respondents scored $\geq 4$ or female respondents scored $\geq 3$, they were determined as AUDIT+ [21,24-30].

- Facebook use and belief of information on Facebook: We asked questions relating to the amount of time individuals spent using Facebook on a daily basis, as well as their primary activity on Facebook. In addition, we asked how participants usually obtained information about medical conditions and health-related conditions. Subsequently, participants were asked whether they had any interest in the health information on Facebook, and they were tasked to estimate the amount of time they spent reading health-related information on Facebook. Participants were asked to rate the perceived level of reliability of the health information, as well as the perceived level of usefulness. Participants were also asked how often they had shared health-related information using the social networking site.

- Interpersonal influence of social network sites: Questions were asked to investigate online peer influence. These included talking with new friends on the Internet, going to places introduced by online friends, effect of online friends 
on behavior and lifestyle, and trying to do something introduced by online friends.

\section{Statistical Analysis}

Chi-square, $t$ test, and analysis of variance were used to explore the differences among characteristics. Multivariate logistic regressions were employed to identify the associated factors. In this study, we applied a stepwise forward model strategy that uses a log-likelihood ratio test at a $P$ value of .10 to select variables for the reduced models [31]. A $P$ value of less than .05 was set as the level of statistical significance.

\section{Ethical Approval}

The Institutional Review Board of the Vietnam Authority of HIV/AIDS Control provided the ethical approval for this study. All participants were asked to provide an electronic informed consent. Participants were briefed and informed that they could withdraw anytime they wanted. Information obtained from the participants was coded and kept confidential.

\section{Results}

A total of 1080 participants took part in the questionnaire survey, out of which $41.94 \%$ (453/1080) were males; $54.26 \%$ $(586 / 1080)$ of the individuals were in the 18 to 22 year age group. The vast majority $(849 / 1080,78.61 \%)$ were undergraduate students, 95.83\% (1035/1080) were of Kinh ethnicity, and $72.59 \%$ (784/1080) were single. A total of $47.59 \%$ (514/1080) of the participants resided in rented accommodations. A total of $9.63 \%(104 / 1080)$ of the participants reported having had acute illnesses in the preceding month, and $18.88 \%$ (204/1080) of the participants reported that they have had chronic illnesses in the last 3 months. Among those sampled, 9.26\% (100/1080) were overweight. In terms of their HRQOL, the vast majority of the participants reported having experienced mood symptoms $(806 / 1080,74.63 \%)$ as well as pain-related symptoms (548/1080, 50.74\%). About $10.74 \%$ (116/1080) of the participants were currently smoking, and twice that $(235 / 1080,21.76 \%)$ were using alcohol. A total of $5.19 \%$ (56/1080) of the participants had also been smoking shisha. The mean scores for all participants on the EQ-5D and EQ-5D VAS were 0.73 and 80.59 , respectively. The mean score for all participants on the PSS was 6.58

Table 1 provides an overview of the baseline use of Facebook by the participants as well as their perceptions about health-related information on Facebook. The average amount of time participants spent on Facebook was 3.05 hours. The mean hours for females and males were 2.98 and 3.14 hours, respectively, and there were no significance differences between the means. The vast majority of the participants $(713 / 1080$, $66.02 \%$ ) used Facebook primarily to keep themselves updated with the latest news. For most participants, friends are regarded as the primary source of their health information. At least $72.9 \%$ (787/1080) of the participants reported that they were interested in the health information shared on Facebook. A total of $65.74 \%$ (710/1080) of the participants spent less than $30 \%$ of the total time they spent on Facebook engaging in and reading health-related information. 
Table 1. Use of Facebook for seeking health information among respondents.

\begin{tabular}{|c|c|c|c|c|}
\hline Characteristics & Female & Male & Total & $P$ value \\
\hline \multicolumn{5}{|l|}{ Primary purpose for using Facebook, n (\%) } \\
\hline Chatting with friends & $143(22.77)$ & $144(31.86)$ & $287(26.57)$ & \multirow[t]{4}{*}{.011} \\
\hline Update news & $436(69.43)$ & $277(61.28)$ & $713(66.02)$ & \\
\hline Counseling & $6(0.96)$ & $4(0.88)$ & $10(0.93)$ & \\
\hline Playing games & $43(6.85)$ & $27(5.97)$ & $70(6.48)$ & \\
\hline \multicolumn{5}{|l|}{ Health information sources, $n(\%)$} \\
\hline Friends & $267(42.52)$ & $239(52.88)$ & $506(46.85)$ & \multirow[t]{4}{*}{.006} \\
\hline Health page/groups & $220(35.03)$ & $130(28.76)$ & $350(32.41)$ & \\
\hline Talk with consultants & $2(0.32)$ & $0(0)$ & $2(0.19)$ & \\
\hline Others & $139(22.13)$ & $83(18.36)$ & $222(20.56)$ & \\
\hline \multicolumn{5}{|l|}{ Interest in health information shared on Facebook, $n(\%)$} \\
\hline Highly interested & $149(23.73)$ & $83(18.36)$ & $232(21.48)$ & \multirow[t]{3}{*}{$<.001$} \\
\hline Interested & $346(55.10)$ & $209(46.24)$ & $555(51.39)$ & \\
\hline Low interest or not interested & $133(21.18)$ & $160(35.40)$ & $293(27.13)$ & \\
\hline \multicolumn{5}{|l|}{ Time spent reading health information on Facebook, $n(\%)$} \\
\hline$<10 \%$ & $164(26.11)$ & $178(39.38)$ & $342(31.67)$ & \multirow[t]{6}{*}{$<.001$} \\
\hline $10 \%-<30 \%$ & $224(35.67)$ & $144(31.86)$ & $368(34.07)$ & \\
\hline $30 \%-50 \%$ & $118(18.79)$ & $64(14.16)$ & $182(16.85)$ & \\
\hline $50 \%-70 \%$ & $62(9.87)$ & $25(5.53)$ & $87(8.06)$ & \\
\hline$>70 \%$ & $6(0.96)$ & $4(0.88)$ & $10(0.93)$ & \\
\hline Unknown & $54(8.60)$ & $37(8.19)$ & $91(8.43)$ & \\
\hline Time spent using Facebook per day (hours), mean (SD) & $2.98(2.562)$ & $3.14(2.901)$ & $3.05(2.713)$ & .351 \\
\hline
\end{tabular}

There were, however, statistically significant differences between the genders in terms of their primary purposes of using Facebook $(P=.011)$, their health information sources $(P=.006)$, their level of interest in health information $(P<.001)$, and the amount of time they spent reading health-related information $(P<.001)$

Table 2 provides a detailed analysis of the participant perceptions of the usefulness and reliability of health-related information on Facebook. A total of 50.65\% (547/1080) of the participants reported that they felt that the information was moderately reliable, and $17.50 \%(189 / 1080)$ reported that the information was highly reliable. Only $4.91 \%$ (53/1080) of the participants perceived the information to be useful. The vast majority of the participants $(629 / 1080,58.24 \%)$ felt that the information was neither useful nor useless. Only $31.20 \%$ (337/1080) of the sampled participants reported that they would not share the health information on Facebook. A cumulative total of $10.93 \%(118 / 1080)$ of participants reported that they would follow the health advisory shared on Facebook. There are significant differences between the genders in all the domains discussed.

Table 3 highlights the interpersonal influence of Facebook and social media sites on respondents. Among the participants, $8.17 \%$ (79/967) reported that social media encourages them to either talk to or meet new friends online. In addition, $7.07 \%$ (68/962) reported that their behaviors, lifestyle, and perceptions are highly affected by others whom they have met online. Of significance, approximately $13.40 \%$ (129/963) of participants reported that they ventured to a new place that was introduced by their online friends. In addition, $8.58 \%$ (83/967) of participants also reported that they often would try out new activities introduced by their online peers. There was no noted significant difference among the genders and the interpersonal influence, as the $P$ values obtained were all not significant. 
Table 2. The belief of respondents in health information on Facebook.

\begin{tabular}{|c|c|c|c|c|}
\hline Characteristics & $\begin{array}{l}\text { Female } \\
\mathrm{n}(\%)\end{array}$ & $\begin{array}{l}\text { Male } \\
\text { n (\%) }\end{array}$ & $\begin{array}{l}\text { Total } \\
\mathrm{n}(\%)\end{array}$ & $P$ value \\
\hline \multicolumn{5}{|c|}{ Reliability of health information shared on Facebook } \\
\hline Low & $134(21.34)$ & $160(35.40)$ & $294(27.22)$ & $<.001$ \\
\hline Moderate & $364(57.96)$ & $183(40.49)$ & $547(50.65)$ & \\
\hline High & $106(16.88)$ & $83(18.36)$ & $189(17.50)$ & \\
\hline Unknown & $24(3.82)$ & $26(5.75)$ & $50(4.63)$ & \\
\hline \multicolumn{5}{|c|}{ Usefulness of health information shared on Facebook } \\
\hline Not useful & $242(38.54)$ & $156(34.51)$ & $398(36.85)$ & $<.001$ \\
\hline Normal & $370(58.92)$ & $259(57.30)$ & $629(58.24)$ & \\
\hline Useful & $16(2.55)$ & $37(8.19)$ & $53(4.91)$ & \\
\hline \multicolumn{5}{|c|}{ Frequency of sharing health information on Facebook } \\
\hline Always & $23(3.66)$ & $34(7.52)$ & $57(5.28)$ & .002 \\
\hline Often & $35(5.57)$ & $30(6.64)$ & $65(6.02)$ & \\
\hline Occasionally & $388(61.78)$ & $233(51.55)$ & $621(57.50)$ & \\
\hline Never & $182(28.98)$ & $155(34.29)$ & $337(31.20)$ & \\
\hline \multicolumn{5}{|c|}{ Practice health information on Facebook } \\
\hline Always & $18(2.87)$ & $20(4.42)$ & $38(3.52)$ & $<.001$ \\
\hline Often & $49(7.80)$ & $31(6.86)$ & $80(7.41)$ & \\
\hline Occasionally & $508(80.89)$ & $320(70.80)$ & $828(76.67)$ & \\
\hline Never & $53(8.44)$ & $81(17.92)$ & $134(12.41)$ & \\
\hline
\end{tabular}

Table 3. Interpersonal influence on Internet among respondents.

\begin{tabular}{|c|c|c|c|c|}
\hline Characteristics & $\begin{array}{l}\text { Female } \\
\mathrm{n}(\%)\end{array}$ & $\begin{array}{l}\text { Male } \\
\text { n (\%) }\end{array}$ & $\begin{array}{l}\text { Total } \\
\text { n (\%) }\end{array}$ & $P$ value \\
\hline \multicolumn{5}{|l|}{ Talk and meet new online friends } \\
\hline Often & $30(5.39)$ & $49(11.95)$ & $79(8.17)$ & $<.001$ \\
\hline Frequently & $101(18.13)$ & $140(34.15)$ & $241(24.92)$ & \\
\hline Rarely or never & $426(76.48)$ & $221(53.90)$ & $647(66.91)$ & \\
\hline \multicolumn{5}{|c|}{ Effects of online relationships on behaviors, lifestyle, and perceptions } \\
\hline High influence & $36(6.46)$ & $32(7.90)$ & $68(7.07)$ & .466 \\
\hline Normal influence & $138(24.78)$ & $89(21.98)$ & $227(23.60)$ & \\
\hline Low influence or no influence & $383(68.76)$ & $284(70.12)$ & $667(69.33)$ & \\
\hline \multicolumn{5}{|c|}{ Go to places introduced by online friends } \\
\hline Often & $79(14.21)$ & $50(12.29)$ & $129(13.40)$ & .685 \\
\hline Frequently & $294(52.88)$ & $221(54.30)$ & $515(53.48)$ & \\
\hline Rarely or never & $183(32.91)$ & $136(33.42)$ & $319(33.13)$ & \\
\hline \multicolumn{5}{|c|}{ Try to do something introduced by online friends } \\
\hline Often & $47(8.44)$ & $36(8.78)$ & $83(8.58)$ & .671 \\
\hline Frequently & $274(49.19)$ & $212(51.71)$ & $486(50.26)$ & \\
\hline Rarely or never & $236(42.37)$ & $162(39.51)$ & $398(41.16)$ & \\
\hline
\end{tabular}

Multimedia Appendix 1 provides an overview of the multivariate regression analysis to determine factors that are associated with health-related information-seeking using Facebook. Males (odds http://www.i-jmr.org/2017/2/e16/ ratio [OR] $0.42,95 \% \mathrm{CI} 0.31-0.58$ ) are less likely to be concerned about health-related information on Facebook. Those participants who have reported increased levels of perceived 
stress, as determined by their scores on the PSS, are also less likely to be interested in and concerned about health information (OR 0.89, 95\% CI 0.83-0.95). Factors that mediate whether participants believe the health information they have acquired from Facebook are affected by sociodemographic variables such as age and education. Participants who are older are less likely to believe in the health information provided on Facebook (OR $0.87,95 \%$ CI $0.80-0.95)$. Participants with vocational training education status are more likely to belief in the health information on Facebook as compared to those with university or postgraduate education. The analysis of interpersonal influences was conducted as we need to determine whether it is one of the associated factors that might mediate the sharing of health-related information by participants. Participants who tend to make use of social media like Facebook to form new relationships (OR 2.65, 95\% CI 1.26-5.56) and participants who are easily influenced by their online peers (OR 2.20, 95\% CI 1.05-4.60) are more likely to share health-related information using their social networking accounts. With regard to whether participants would adhere to the health information provided on the social network, being of male gender has been found to be negatively associated with adherence (OR $0.84,95 \% \mathrm{CI}$ 0.76-0.93). However, interpersonal factors like using the social network to find new friends and following the advice of online peers are associated with a heightened incidence of adhering to the health information provided. Of significance, health information is commonly perceived to be useful among those individuals who are overweight.

\section{Discussion}

\section{Principal Findings}

This is one of the first studies conducted in Vietnam that looks into the relationship between health information on Facebook and associated factors that might influence Vietnamese perceptions of the information and their use of the information that they have obtained from social networking sites. In our study, a total of 1080 participants took part and the vast majority were undergraduate students. A total of $18.88 \%$ (204/1080) of the participants reported that they have had health issues over the past 3 months, $9.26 \%$ (100/1080) of them were overweight, and a significant proportion have had pain or mood-related symptoms. Among the participants, 72.90\% (787/1080) of them reported that they were interested in the health information on Facebook, and 50.65\% (547/1080) and 17.50\% (189/1080) perceived the information to be reliable and useful, respectively. A total of $10.93 \%(108 / 1080)$ of the participants also reported that they would follow the health advice they obtained from Facebook. Of significance, 7.07\% (68/1080) of the participants also reported peer influences on their behaviors. Factors that mediate Vietnamese perceptions of the information online include gender, level of perceived stress, age, educational level, and interpersonal influences of Facebook. These factors moderated and affected how Vietnamese perceive the usefulness and reliability of the health information, as well as the likelihood that they would share the information with their peers.

There have been prior studies conducted in China looking at the equivalents of social networking sites like Facebook and determining factors that might affect how their cohort used social networks [32]. One study reported that Internet self-efficacy is a mediating factor influencing use [32]. Other studies have looked into specific ethnicity and how ethnicity in itself might be a mediating factor affecting use [33]. Lee [33] reported that as many as $98 \%$ of African American college students had a Facebook account and were actively using Facebook. In addition, younger users reported spending more time online. A study also reported how cultural factors could influence use [33]. Cultural factors do have a significant influence on the motivation to use Facebook as well as the amount of time devoted to using it. Underwood et al [34] reported that there are fundamentally 3 different types of users - broadcasters, communicators, and high interactors - and the use of Facebook differs among these groups. Other comparative studies have reported on how women from different cultures use Facebook differently [35]. For example, Americans tend to seek out Facebook for entertainment, whereas Koreans tend to seek social support and information online [34-36]. These previous studies highlight the prevalent usage of Facebook across various countries and that the usage might be mediated and influenced highly by cultural variable. Our study has reported that among our sampled cohort of Vietnamese, a good number of individuals were using Facebook and that the mean duration of use was 3.05 hours. In our study, we found that the vast majority of the participants have used Facebook to keep themselves updated about the latest news. The findings from our study are much in line with that of Kim et al [36], and this was expected as ours is an Asian cohort.

Our study, which looks into the acceptability and receptiveness of youths toward health information available on Facebook, is crucial, as a prior study has examined how social media could be used by community-based organizations who are conducting health promotion [37]. That study has examined social networking sites such as Facebook, Twitter, and YouTube and found that these social media networks helped in the dissemination of health information to participants [37]. Our study finds that Facebook could potentially be a good medium for the dissemination of health-related information, given that a good number of our sampled participants believe in the reliability of the information and are keen to share the information.

In our study, we found that males are less likely comparatively to be concerned about health-related information on Facebook. The fact that males are less likely to be concerned about health-related information might be accounted for by gender differences in the usage of Facebook. Raacke and Bonds-Raccke [38] reported that males tend to have a larger social network on Facebook and tend to make use of Facebook for dating-related purposes. In addition, we found that educational level would mediate whether participants believe the health-related information they have obtained online. Of significance, those with only a vocational level of education are more likely to believe the information online as compared to those with higher levels of education. We postulate that this might be related to how participants process the information by determining the accuracy and source of the information. Those with higher levels 
of education are more likely to consider the accuracy as well as the original source of the health-related information.

In addition, in our study we have determined that Facebook is associated with significant interpersonal influence. A prior study by Hormes [39] has suggested that the excessive use of Facebook is similar to that of a behavioral form of addiction and demonstrated that those who met the criteria for disordered social networking usage were more likely to use alcohol. While Hormes' study demonstrated the negative impact of Facebook, it has demonstrated that Facebook could potentially shape one's perceptions. In our study, it is likely that Facebook might have caused changes in perceptions toward health-related information, whereas in Hormes' study, Facebook normalized alcohol use and provided opportunities for increased use of alcohol. While there remains to date limited literature on interpersonal influences of Facebook, a previous study examining Internet addiction has demonstrated that those with Internet addiction are more susceptible to interpersonal influences due to their reduced cognitive abilities [15]. We postulate that this might be similar for Facebook users, especially for those who are using Facebook excessively.

There are several clinical implications that arise from our study. Given the results, clinicians should be aware that youths and young adults are increasingly exposed to health-related information on social media. Hence, there is a good potential for the use of social media to augment the conventional mechanism of delivery of health-related information. Clinicians should know that information gotten from Facebook might not be entirely factually correct and should provide evidence-based information and recommendations about the various diseases to their patients. It is important to tale gender and educational influences into consideration and for there to be tailored and customizable messages. Clinicians should recognize the role of social media in their outreach efforts because we have found in this study that social media has interpersonal influences and messages that are disseminated could have potentially positive or negative outcomes. Hence, in using Facebook as a medium for health information dissemination, there needs to be some moderation of the content that is posted online. There has been recent research demonstrating how social media use could help in public health campaigning, especially in a low-resource setting [40]. The authors have reported how effective such media are, given that they have inherent potential for rapid transfer of information to the masses [40].

\section{Strengths and Limitations}

Our study aimed to determine the use rates of social networking sites among young Vietnamese. Our study is perhaps one of the first studies examining the rates of social media use to be conducted in a developing country like Vietnam. We recruited a sizeable number of participants who, at the baseline, had knowledge of how to use the Internet (because they were required to make use of the Internet to take part in our survey). In addition, we were able to determine their perceptions and beliefs about health-related information shared on social networking sites as well as the interpersonal influences of social networking sites. We identified their baseline health status and other demographic variables and the influence of these variables on their perceptions of the health-related information shared online. Despite the clear strengths of our study, we do acknowledge several inherent limitations. Our sampled cohort might not be entirely representative of the general Vietnamese population. However, Internet-based sampling is the most effective low-cost way to reach out to individuals in a developing country like Vietnam. Also, our sampling is dependent on RDS and hence our participants needed to have social networking accounts to recruit other participants. We have only examined individual perceptions toward health-related information in general. Ideally, it would be of importance to determine their perceptions toward particular health-related information such as particular diseases, and this will help guide our future interventions.

\section{Conclusion}

This study is perhaps one of the pioneering studies conducted in Vietnam looking at the relationship between health information on Facebook and factors that might influence young Vietnamese perceptions of the information and the consequential use of that information. Clearly, from our study, a good proportion of young Vietnamese use social media to check out health-related information and share this information with their peers. Factors that mediate Vietnamese perceptions of the information online include gender, level of perceived stress, age, educational level, and interpersonal influences of Facebook. The above findings have clinical implications for clinicians who might wish to consider social sites for health-related interventions.

\section{Acknowledgments}

The authors would like to acknowledge support by the Vietnam Authority of HIV/AIDS Control for the implementation of the study.

\section{Conflicts of Interest}

None declared.

\section{Multimedia Appendix 1}

Associated factors with health information seeking behaviors and belief on Facebook among respondents.

\section{[PDF File (Adobe PDF File), 22KB-Multimedia Appendix 1]}




\section{References}

1. O'Carroll AM, Westby EP, Dooley J, Gordon KE. Information-seeking behaviors of medical students: a cross-sectional Web-based survey. JMIR Med Educ 2015 Jun 29;1(1):e4 [FREE Full text] [doi: 10.2196/mededu.4267] [Medline: 27731842]

2. FinTech Singapore. Mobile phone continues to be Vietnam's no. 1 for Internet use. 2016. URL: http://fintechnews.sg/855/ studies/mobile-phone-vietnams-no-1-device-internet-use/ [accessed 2017-08-21] [WebCite Cache ID 6stLc1AEG]

3. eMarketer. Vietnam online: digital usage and behavior, 2015-2020. 2016. URL: https://www.emarketer.com/Report/ Vietnam-Online-Digital-Usage-Behavior-2015-2020/2001971 [accessed 2017-08-21] [WebCite Cache ID 6stLwZ1Sk]

4. Quintero JJM, Yilmaz G, Najarian K. Optimizing the presentation of mental health information in social media: the effects of health testimonials and platform on source perceptions, message processing, and health outcomes. Health Commun 2017 Sep;32(9):1121-1132. [doi: 10.1080/10410236.2016.1214218] [Medline: 27573748]

5. Fergie G, Hilton S, Hunt K. Young adults' experiences of seeking online information about diabetes and mental health in the age of social media. Health Expect 2015 Dec 8;19(6):1324-1335. [doi: 10.1111/hex.12430] [Medline: 26647109]

6. Huesch MD, Galstyan A, Ong MK, Doctor JN. Using social media, online social networks, and Internet search as platforms for public health interventions: a pilot study. Health Serv Res 2016 Jun;51 Suppl 2:1273-1290. [doi: 10.1111/1475-6773.12496] [Medline: 27161093 ]

7. Crosier BS, Brian RM, Ben-Zeev D. Using Facebook to reach people who experience auditory hallucinations. J Med Internet Res 2016;18(6):e160 [FREE Full text] [doi: 10.2196/jmir.5420] [Medline: 27302017]

8. Ridout B, Campbell A. Using Facebook to deliver a social norm intervention to reduce problem drinking at university. Drug Alcohol Rev 2014 Nov;33(6):667-673. [doi: 10.1111/dar.12141] [Medline: 24689339]

9. Gajaria A, Yeung E, Goodale T, Charach A. Beliefs about attention-deficit/hyperactivity disorder and response to stereotypes: youth postings in Facebook groups. J Adolesc Health 2011 Jul;49(1):15-20. [doi: 10.1016/j.jadohealth.2010.09.004] [Medline: 21700151]

10. Syn SY, Kim SU. College students' health information activities on Facebook: investigating the impacts of health topic sensitivity, information sources, and demographics. J Health Commun 2016 Jul;21(7):743-754. [doi: 10.1080/10810730.2016.1157652] [Medline: 27220029]

11. Kousoulis AA, Kympouropoulos SP, Pouli DK, Economopoulos KP, Vardavas CI. From the classroom to Facebook: a fresh approach for youth tobacco prevention. Am J Health Promot 2016 May;30(5):390-393. [doi: 10.1177/0890117116646345] [Medline: 27404648]

12. Minh HV, Minh HV, Giang KB, Hai PT, Hoang TD, Huyen DT, et al. Access to anti-smoking information among school children and its potential impact on preventing smoking initiation: results from the Global Youth Tobacco Use Survey (GYTS) 2014 in Vietnam. Asian Pac J Cancer Prev 2016;17(S1):31-36 [FREE Full text] [Medline: 27087180]

13. Zhang MWB, Tran BX, Huong LT, Hinh ND, Nguyen HLT, Tho TD, et al. Internet addiction and sleep quality among Vietnamese youths. Asian J Psychiatr 2017 Aug;28:15-20 [FREE Full text] [doi: 10.1016/j.ajp.2017.03.025] [Medline: 28784371]

14. Zhang MWB, Tran BX, Nguyen HLT, Le HT, Long NH, Le HT, et al. Using online respondent driven sampling for Vietnamese youths' alcohol use and associated risk factors. Healthc Inform Res 2017 Apr;23(2):109-118 [FREE Full text] [doi: 10.4258/hir.2017.23.2.109] [Medline: 28523209]

15. Tran BX, Huong LT, Hinh ND, Nguyen LH, Le BN, Nong VM, et al. A study on the influence of internet addiction and online interpersonal influences on health-related quality of life in young Vietnamese. BMC Public Health 2017 Jan 31;17(1):138 [FREE Full text] [doi: 10.1186/s12889-016-3983-z] [Medline: 28143462]

16. Tran BX, Ohinmaa A, Nguyen LT. Quality of life profile and psychometric properties of the EQ-5D-5L in HIV/AIDS patients. Health Qual Life Outcomes 2012 Nov 01;10:132 [FREE Full text] [doi: 10.1186/1477-7525-10-132] [Medline: 23116130]

17. Nguyen LH, Nguyen HTT, Nguyen HLT, Tran BX, Latkin CA. Adherence to methadone maintenance treatment and associated factors among patients in Vietnamese mountainside areas. Subst Abuse Treat Prev Policy 2017 Jun 08;12(1):31 [FREE Full text] [doi: 10.1186/s13011-017-0115-4] [Medline: 28595642]

18. Nguyen LH, Nguyen LHT, Boggiano VL, Hoang CD, Van NH, Le HT, et al. Quality of life and healthcare service utilization among methadone maintenance patients in a mountainous area of Northern Vietnam. Health Qual Life Outcomes 2017 Apr 20;15(1):77 [FREE Full text] [doi: 10.1186/s12955-017-0633-9] [Medline: 28427471]

19. Nguyen LH, Tran BX, Nguyen HLT, Nguyen CT, Hoang CD, Le HQ, et al. Psychological distress among methadone maintenance patients in Vietnamese mountainous areas. AIDS Behav 2017 Apr 24. [doi: 10.1007/s10461-017-1779-5] [Medline: 28439756]

20. Van Nguyen NH, Nguyen HLT, Mai HT, Le HQ, Tran BX, Hoang CD, et al. Stigmatization among methadone maintenance treatment patients in mountainous areas in northern Vietnam. Harm Reduct J 2017 Jan 06;14(1):1 [FREE Full text] [doi: 10.1186/s12954-016-0127-9] [Medline: 28056990]

21. Tran BX, Nguyen LH, Nong VM, Nguyen CT. Health status and health service utilization in remote and mountainous areas in Vietnam. Health Qual Life Outcomes 2016 Jun 7;14(1). [doi: 10.1186/s12955-016-0485-8] 
22. Tran BX, Nguyen LH, Phan HTT, Nguyen LK, Latkin CA. Preference of methadone maintenance patients for the integrative and decentralized service delivery models in Vietnam. Harm Reduct J 2015 Sep 17;12:29 [FREE Full text] [doi: 10.1186/s12954-015-0063-0] [Medline: 26377824]

23. Karam F, Bérard A, Sheehy O, Huneau M, Briggs G, Chambers C, OTIS Research Committee. Reliability and validity of the 4-item perceived stress scale among pregnant women: results from the OTIS antidepressants study. Res Nurs Health 2012 Aug;35(4):363-375. [doi: 10.1002/nur.21482] [Medline: 22511354]

24. Tran BX, Nguyen N, Ohinmaa A, Duong AT, Nguyen LT, Vu PX, et al. Prevalence and correlates of alcohol use disorders during antiretroviral treatment in injection-driven HIV epidemics in Vietnam. Drug Alcohol Depend 2013 Jan 01;127(1-3):39-44. [doi: 10.1016/j.drugalcdep.2012.06.009] [Medline: 22749565]

25. Tran BX, Nguyen LT, Do CD, Nguyen QL, Maher RM. Associations between alcohol use disorders and adherence to antiretroviral treatment and quality of life amongst people living with HIV/AIDS. BMC Public Health 2014 Jan 10;14:27 [FREE Full text] [doi: 10.1186/1471-2458-14-27] [Medline: 24411007]

26. Bradley KA, DeBenedetti AF, Volk RJ, Williams EC, Frank D, Kivlahan DR. AUDIT-C as a brief screen for alcohol misuse in primary care. Alcohol Clin Exp Res 2007 Jul;31(7):1208-1217. [doi: 10.1111/j.1530-0277.2007.00403.x] [Medline: 17451397]

27. Tran BX, Nguyen LH, Nguyen CT, Phan HTT, Latkin CA. Alcohol abuse increases the risk of HIV infection and diminishes health status of clients attending HIV testing services in Vietnam. Harm Reduct J 2016 Feb 16;13:6 [FREE Full text] [doi: 10.1186/s12954-016-0096-z] [Medline: 26879232]

28. Tran BX, Nguyen LH, Nguyen LP, Nguyen CT, Phan HTT, Latkin CA. Methadone maintenance treatment promotes referral and uptake of HIV testing and counselling services amongst drug users and their partners. PLoS One 2016;11(4):e0152804 [FREE Full text] [doi: 10.1371/journal.pone.0152804] [Medline: 27046029]

29. Tran BX, Nguyen LH, Nong VM, Nguyen CT, Phan HTT, Latkin CA. Behavioral and quality-of-life outcomes in different service models for methadone maintenance treatment in Vietnam. Harm Reduct J 2016 Feb 02;13:4 [FREE Full text] [doi: 10.1186/s12954-016-0091-4] [Medline: 26837193]

30. Tran BX, Vu PB, Nguyen LH, Latkin SK, Nguyen CT, Phan HTT, et al. Drug addiction stigma in relation to methadone maintenance treatment by different service delivery models in Vietnam. BMC Public Health 2016 Mar 08;16:238 [FREE Full text] [doi: 10.1186/s12889-016-2897-0] [Medline: 26956741]

31. Hosmer Jr D. Applied Logistic Regression. 3rd Edition. Hoboken: Wiley Publishing; 2013.

32. Shi J, Niu Q. SNSs usage among Chinese internet users: an empirical study. Stud Health Technol Inform 2010;154:150-154. [Medline: 20543288]

33. Lee EB. Young, black, and connected: Facebook usage among African American college students. J Black Stud 2012;43(3):336-354. [Medline: 22536626]

34. Underwood J, Kerlin L, Farrington-Flint L. The lies we tell and what they say about us: using behavioural characteristics to explain Facebook activity. Comput Hum Behav 2011;27(5):1621-1626.

35. Barker V, Ota H. Mixi diary versus Facebook photos: social networking site use among Japanese and Caucasian American females. J Intercultural Comm Res 2011 Mar;40(1):39-63. [doi: 10.1080/17475759.2011.558321]

36. Kim Y, Sohn D, Choi S. Cultural difference in motivations for using social network sites: a comparative study of American and Korean college students. Comput Hum Behav 2011;27(1):1.

37. Ramanadhan S, Mendez SR, Rao M, Viswanath K. Social media use by community-based organizations conducting health promotion: a content analysis. BMC Public Health 2013;13:1129 [FREE Full text] [doi: 10.1186/1471-2458-13-1129] [Medline: 24313999]

38. Raacke J, Bonds-Raacke J. MySpace and Facebook: applying the uses and gratifications theory to exploring friend-networking sites. Cyberpsychol Behav 2008 Apr;11(2):169-174. [doi: 10.1089/cpb.2007.0056] [Medline: 18422409]

39. Hormes JM. Under the influence of Facebook? Excess use of social networking sites and drinking motives, consequences, and attitudes in college students. J Behav Addict 2016 Mar;5(1):122-129 [FREE Full text] [doi: 10.1556/2006.5.2016.007] [Medline: 28092186]

40. Jawad M, Abass J, Hariri A, Akl EA. Social media use for public health campaigning in a low resource setting: the case of waterpipe tobacco smoking. Biomed Res Int 2015;2015:562586 [FREE Full text] [doi: 10.1155/2015/562586] [Medline: 26273631]

\section{Abbreviations}

AUDIT-C: Alcohol Use Disorders Identification Test-Consumption

EQ-5D-5L: EuroQol 5 dimension 5 level questionnaire

HRQOL: health-related quality of life

OR: odds ratio

PSS: Perceived Stress Scale

RDS: respondent-driven sampling

VAS: visual analog scale 
Edited by G Eysenbach; submitted 20.05.17; peer-reviewed by L Nguyen, L Nguyen; comments to author 08.06.17; revised version received 13.07.17; accepted 27.07.17; published 07.09.17

Please cite as:

Zhang MWB, Tran BX, Le HT, Nguyen HD, Nguyen CT, Tran TD, Latkin CA, Ho RCM

Perceptions of Health-Related Information on Facebook: Cross-Sectional Study Among Vietnamese Youths

Interact J Med Res 2017;6(2):e16

URL: http://www.i-jmr.org/2017/2/e16/

doi: 10.2196/ijmr.8072

PMID: 28882813

CMelvyn WB Zhang, Bach Xuan Tran, Huong Thi Le, Hinh Duc Nguyen, Cuong Tat Nguyen, Tho Dinh Tran, Carl A Latkin, Roger CM Ho. Originally published in the Interactive Journal of Medical Research (http://www.i-jmr.org/), 07.09.2017. This is an open-access article distributed under the terms of the Creative Commons Attribution License (https://creativecommons.org/licenses/by/4.0/), which permits unrestricted use, distribution, and reproduction in any medium, provided the original work, first published in the Interactive Journal of Medical Research, is properly cited. The complete bibliographic information, a link to the original publication on http://www.i-jmr.org/, as well as this copyright and license information must be included. 